\title{
Noninvasive Assessment of Artery Wall Properties in Children Aged 4-19 Years
}

\author{
T. VAN MERODE, P. J. J. HICK, A. P. G. HOEKS, AND R. S. RENEMAN \\ Departments of Physiology and Biophysics, University of Limburg, Maastricht, The Netherlands
}

\begin{abstract}
The vessel wall properties of the common carotid artery were noninvasively studied in 53 normotensive, presumed normal boys of various ages (4-19 yr) with the use of a multigate pulsed Doppler system. This device allows the on-line recording of velocity profiles and the relative changes in carotid artery diameter during the cardiac cycle. From the width of these profiles, the internal diameter of the carotid artery can be determined. With the use of internal carotid artery diameter, relative changes in carotid artery diameter during the cardiac cycle, and pulse pressure the pulse pressure, as measured in the brachial artery, the distensibility coefficient and the cross-sectional compliance were calculated. The children were allotted to three different age groups: group I (4-10 yr), group II (11$14 \mathrm{yr})$, and group III (15-19 yr). In the older children (group III) the systolic arterial pressure and the pulse pressure were significantly higher than in groups I and II. The carotid artery diameter was significantly larger and the distensibility coefficient was significantly smaller in group III than in groups I and II. The cross-sectional compliance was not significantly different in the age groups, which can be explained by the larger artery diameter in the older age group. The findings indicate that the carotid artery wall is less distensible in adolescents than in younger children. The subjects in group III showed similar carotid artery wall properties as the young adults (aged 20-34 yr) in a previous study. Therefore, it is likely that in adolescents the vascular system can be considered as mature as far as the arterial wall properties are concerned. (Pediatr Res 25:94-96, 1988)
\end{abstract}

\section{Abbreviations}

$\mathbf{P}_{\mathrm{s}}$, systolic arterial pressure

$\mathbf{P}_{\mathrm{d}}$, diastolic arterial pressure

$\triangle \mathbf{p}$, pulse pressure

d, internal carotid artery diameter

$\Delta \mathrm{d} / \mathrm{d}$, peak arterial diameter increase during systole

CC, cross-sectional compliance

DC, distensibility coefficient

$\triangle d / d * 100 \%$, relative changes in carotid artery diameter during the cardiac cycle

It has long been known that aging alters the histologic structure of artery walls and, hence, changes their dynamic properties (1). Most of the information available on artery wall properties has been obtained from excised vessels $(2-5)$ or experiments on

Received April 25, 1988; accepted August 30, 1988.

Correspondence T. van Merode, M.D., Department of Physiology, Biomedical Center, University of Limburg, P.O. Box 616, 6200 MD Maastricht, The Netherlands.

Supported by STW Grant MGN25.0258. anesthetized animals $(2,3,6,7)$. The limited number of noninvasive investigations on human arteries nearly all concern adults $(8,9)$. One of these studies $(9)$ showed that carotid artery distensibility and cross-sectional compliance decrease linearly with age, starting in the $3 \mathrm{rd}$ decade. The only study (10) that includes children (6-25 yr) does not provide information about the changes in artery wall properties with age in children and adolescents, because the children were not allotted to different age groups.

It was the aim of our study to investigate the distensibility (the relative increase in arterial diameter during systole normalized with respect to the arterial pulse pressure) and cross-sectional compliance (distensibility multiplied by the arterial diameter) of the common carotid artery in children aged 4-19 yr. The common carotid artery was chosen because it is known to be rather elastic and easily accessible to ultrasound. The relative diameter changes during the cardiac cycle and the vessel diameter were assessed with the use of a specially designed multigate pulsed Doppler system.

\section{MATERIALS AND METHODS}

The study was performed on 53 healthy male volunteers, aged 4-19 yr. The study was limited to male subjects, because in previous studies women were found to have less distensible arteries than men $(10,11)$. The parents responded to a written request asking their children for a short noninvasive examination. The request was handed out at two nearby schools, after consultation with the teachers. In all cases, informed consent of the parent(s) was obtained. All respondents were included in the study. They took no medication, and all had normal arterial blood pressures. The volunteers were allotted to three age groups: group I, 4-9 yr $(n=18)$; group II, $10-14$ yr $(n=25)$; and group III, $15-19$ yr $(n=10)$.

The ultrasound investigations were performed with the subjects in the supine position with the head tilted slightly to the contralateral side. The $\Delta d / d \times 100 \%$ was recorded on-line with a high resolution multigate pulsed Doppler system (12-14). These diameter changes were recorded in the plane of the carotid artery bifurcation. The assessment of vessel wall displacement is based upon the processing of low frequency Doppler signals, originating from the sample volumes coinciding with the anterior and posterior walls. The Doppler signals originating from the walls were $30-100 \times$ higher in amplitude than the signals originating from the slowly moving blood cells close to the vessel wall and, hence, mask the signals induced by these cells completely. The small size of the sample volume excludes contamination with other slowly moving structures $\left(1.2 \mathrm{~mm}^{3}\right.$ at a depth of 15 $\mathrm{mm}$; the width of the ultrasound beam is about $1 \mathrm{~mm}$ at this depth). To ensure that the initial relative change at the beginning of the cardiac cycle is constant, it is reset to 0 by a trigger derived from the R-wave of a standard lead of the ECG. The ECG was also used to calculate heart rate. The relative arterial diameter changes are independent of the angle of interrogation and can 
be determined with an absolute accuracy of $0.5 \%$ (15), comparing favorably to the peak excursions observed. This means that for a relative excursion of, for instance, $7 \%$ a relative change in diameter between $6.5-7.5 \%$ can be measured. The coefficient of variation in assessing relative arterial diameter changes was found to be $10.7 \%$ when volunteers were investigated $2 \times$ at intervals of 2 to $6 \mathrm{wk}$ (unpublished results). The multigate pulsed Doppler system also allows the on-line recording of velocity profiles in arteries, that is, the velocity distribution over the cross-sectional area of the vessel, at discrete time intervals during the cardiac cycle $(9,13,14)$. From the width of these velocity profiles, the internal diameter of an artery can be assessed rather accurately with an error about $0.7 \mathrm{~mm}$. Inasmuch as the multigate pulsed Doppler system shows on-line the gates that display blood velocity, city, the largest diameter can be found by assessing the maximal number of adjacent gates showing velocity. Because the arterial diameter, as obtained in this way, is dependent on the angle of interrogation, the values measured were corrected for this angle, i.e., $60^{\circ}$ in the present study. The relative arterial diameter changes during the cardiac cycle and the diameter of the common carotid artery were determined approximately 3 $\mathrm{cm}$ proximal to the carotid artery bifurcation. The site of measurement was localized through a velocity image of the bifurcation (16). In this technique, a transducer of a Doppler system is connected to a mechanical scanning arm. The position of the transducer and beam is electronically sensed by position sensing circuitry which causes the beam of an image storage oscilloscope to move in correspondence with the position of the transducer. The output of the Doppler system intensifies the Z-axis of the image storage oscilloscope only for a given direction of flow, and the threshold of the Z-axis beam control circuit is set so that only signals above, for instance, $10 \%$ of peak flow will be imaged. By repeatedly passing the transducer over the artery and following the artery along its course, a two-dimensional picture of arteries can be made. The image formed is similar to the anatomic display of x-ray arteriography, but represents a functional projection of local blood flow velocities.

At the time of the examination, brachial artery cuff blood pressure measurements were performed with the subjects in the supine position according to the technique described by Savage et al. (17). When assessed in this way, the diastolic pressure values (disappearance of the sounds) correlate well with those determined invasively (17). The width of the cuff was adapted to the upperarm circumference of the children in the various age groups (group I, $11 \mathrm{~cm}$; groups II and III, $14 \mathrm{~cm}$ ). The measurements were repeated $2-3$ times, and the lowest value was taken as the subject's reading. The arterial $\Delta \mathrm{p}$, that is the difference between systolic and diastolic blood pressure, was estimated from this pressure reading. The peak systolic value of $\Delta d / d$ and the absolute $d$ and $\triangle p$ values were used to calculate the DC and $C C$, as previously described in detail $(9,18)$, with the use of the following equations:

$$
\begin{gathered}
\mathrm{DC}=\frac{2 \Delta \mathrm{d} / \mathrm{d}}{\Delta \mathrm{p}} \\
\mathrm{CC}=\frac{\Delta \mathrm{d} / \mathrm{d}}{2 \Delta \mathrm{p}} \cdot \pi \mathrm{d}^{2}
\end{gathered}
$$

Differences between the groups were evaluated for statistical significance with the use of the nonparametric Kruskal-Wallis test. A $p$ value $<0.05$ was considered to be a significant difference.

\section{RESULTS}

The values for age, $\mathrm{P}_{\mathrm{s}}$, and $\mathrm{P}_{\mathrm{d}}, \Delta \mathrm{p}, \Delta \mathrm{d} / \mathrm{d} * 100 \%, \mathrm{~d}, \mathrm{DC}$, and $\mathrm{CC}$ in the various age groups are presented in Table 1 . There were no significant differences for any of the variables studied between groups I and II. In group III, the carotid artery diameter (d) was significantly larger, and the systolic arterial pressure and
Table 1. $P_{s}$ and $P_{d}$ arterial pressure, $\Delta p, \Delta d / d, d, D C$, and $C C$ in the three age groups (mean $\pm S D$ )

\begin{tabular}{lccc}
\hline & $\begin{array}{c}\text { Group I } \\
(4-9 \mathrm{yr}) \\
n=18\end{array}$ & $\begin{array}{c}\text { Group II } \\
(10-14 \mathrm{yr}) \\
n=25\end{array}$ & $\begin{array}{c}\text { Group III } \\
(15-19 \mathrm{yr}) \\
n=10\end{array}$ \\
\hline Age $(\mathrm{yr})$ & $7.67 \pm 1.5$ & $11.6 \pm 1.6$ & $17.1 \pm 1.7$ \\
$\mathrm{P}_{\mathrm{s}}(\mathrm{mm} \mathrm{Hg})$ & $110.0 \pm 3.2$ & $114.5 \pm 8.6$ & $125.7 \pm 9.8^{*}$ \\
$\mathrm{P}_{\mathrm{d}}(\mathrm{mm} \mathrm{Hg})$ & $66.0 \pm 8.0$ & $65.5 \pm 8.6$ & $67.1 \pm 3.9$ \\
$\Delta \mathrm{p}(\mathrm{mm} \mathrm{Hg})$ & $43.4 \pm 8.1$ & $49.2 \pm 12.3$ & $59.3 \pm 11.0^{*}$ \\
$\Delta \mathrm{d} / \mathrm{d}(\%)$ & $9.1 \pm 1.3$ & $9.8 \pm 2.0$ & $8.9 \pm 1.7$ \\
$\mathrm{~d}(\mathrm{~mm})$ & $5.5 \pm 0.6$ & $5.8 \pm 0.8$ & $6.5 \pm 0.7^{*}$ \\
$\mathrm{DC}\left(10^{-3} / \mathrm{KPa}\right)$ & $31.4 \pm 4.5$ & $29.8 \pm 6.1$ & $22.5 \pm 4.3^{*}$ \\
$\mathrm{CC}\left(10^{-7} \mathrm{~m}^{2} / \mathrm{KPa}\right)$ & $7.6 \pm 1.1$ & $7.9 \pm 1.6$ & $7.5 \pm 1.4$ \\
\hline
\end{tabular}

* Significantly different from the values in groups I and II $(p<0.05)$.

the pulse pressure were significantly higher than in groups I and II. The DC was significantly lower in group III than in groups I and II. CC was not significantly different in the three groups.

\section{DISCUSSION}

The common carotid artery is less distensible in adolescents than in younger children, as indicated by the diminished DC in children aged 15-19 yr, as compared with children 4-14 yr of age. The diminished distensibility is not associated with a decrease in $\mathrm{CC}$ because the $\mathrm{d}$ is larger in the older children. In this way, the capacity to store energy temporarily in the common carotid artery, as during a heartbeat, is preserved with increasing age, despite the loss of distensibility.

To evaluate whether the vascular system in group III can be considered to be mature, the arterial wall properties in this age category were compared with those assessed in our laboratory in a previous study on healthy normotensive males aged 20-34 yr (19). In this study, the distensibility coefficient of the common carotid artery was found to be $20.0 \pm 5.110^{-3} / \mathrm{kPa}$ (mean $\pm \mathrm{SD}$ ) and the cross-sectional compliance $6.5 \pm 1.710^{-7} \mathrm{~m}^{2} / \mathrm{Kpa}$ (mean \pm SD). These values are not significantly different from those found in group III (Mann-Whitney test). The adult blood pressure values $\left(\mathrm{P}_{\mathrm{s}}=128 \pm 8 \mathrm{~mm} \mathrm{Hg}, \mathrm{P}_{\mathrm{d}}=71.2 \pm 6.5 \mathrm{~mm} \mathrm{Hg}, \Delta \mathrm{p}\right.$ $=55.8 \pm 9.3 \mathrm{~mm} \mathrm{Hg}$ ) were not significantly different from the adolescent values either (Mann-Whitney test).

These findings indicate that the vascular system can be considered to be mature at the adolescent age as far as arterial wall properties are concerned. The less distensible arterial wall in older than in younger children is likely to be responsible for the higher systolic arterial pressure in the adolescents. Because diastolic arterial pressure is not significantly different in the three age groups, indicating that peripheral vascular resistance is similar in these groups, arterial pulse pressure is higher in older than in younger children. The comparable degree of distensibility of the arterial wall in young adults and adolescents likely explains the similar systolic arterial pressure and arterial pulse pressure values in the two age categories.

\section{REFERENCES}

1. Kohn RR 1977 Heart and cardiovascular system. In: Finch CE, Hayflinck L (eds) Handbook of the Biology of Aging. Van Nostrand Reinhold Company, New York

2. Bergel DH 1972 Cardiovascular Fluid Dynamics. Academic Press, New York

3. McDonald DA 1974 Blood Flow in Arteries. Williams \& Wilkins, Baltimore

4. Learoyd BM, Taylor MG 1966 Alterations with age in the viscoelastic properties of human arterial walls. Circ Res 18:278-292

5. Roach MR 1970 The static elastic properties of carotid arteries from fetal sheep. Can J Physiol Pharmacol 48:695-708

6. Nicolosi GR, Pieper HP 1971 Nature of aortic smooth muscle responses to changes in venous return studied in intact dogs. Am J Physiol 221:12091216

7. Pagani M, Mirsky I, Baig H, Manders WT, Kerkhof P, Vater SF 1979 Effects of age on aortic pressure-diameter and elastic stiffness-stress relationships in unanesthetized sheep. Circ Res 44:420-429

8. Mozersky DJ, Sumner DD, Hokanson DE, Strandness DE 1972 Transcuta- 
neous measurement of the elastic properties of the human femoral artery. Circulation 46:948-955

9. Reneman RS, van Merode T, Hick PJJ, Muytjens AMM, Hoeks APG 1986 Age related changes in carotid artery wall properties in men. Ultrasound Med Biol 12:456-471

10. Riley WA, Barnes RW, Schey HM 1984 An approach to the non-invasive periodic assessment of arterial elasticity in the young. Prev Med 13:169-184

11. Van Merode T, Hick PJJ, Hoeks APG, Smeets FAM, Reneman RS 1988 Differences in carotid artery wall properties between presumed-healthy men and women. Ultrasound Med Biol, in press

12. Reneman RS, Van Merode T, Hick P, Hoeks APG 1986 Cardiovascular applications of multi-gate pulsed Doppler systems. Ultrasound Med Biol 12:357-370

13. Hoeks APG, Reneman RS, Peronneau PA 1981 A multigate pulsed Doppler system with serial data processing. IEEE Trans Sonics Ultrasonc SU-28:242247
14. Hoeks APG 1982 On the development of a multigate pulsed Doppler system with serial data-processing. Thesis, University of Limburg, Maastricht, The Netherlands

15. Hoeks APG, Ruissen CJ, Hick PJJ, Reneman RS 1985 Transcutaneous detection of relative changes in artery diameter. Ultrasound Med Biol 11:51-59

16. Reneman RS, Spencer MP 1979 Local Doppler audio spectra in normal and stenosed carotid arteries in man. Ultrasound Med Biol 5:1-11

17. Savage JM, Dillon MJ, Taylor JFN 1979 Clinical evaluation and comparison of the infrasonde, arteriosonde, and mercury sphygmomanometer in measurement of blood pressure in children. Arch Dis Child 54:184-189

18. Van Merode T, Hick PJJ, Hoeks APG, Rahn KH, Reneman RS 1988 Carotid artery wall properties in normotensive and borderline hypertensive subjects of various ages. Ultrasound Med Biol, in press

19. Van Merode T, Hick PJJ, Hoeks APG, Rahn KH, Reneman RS 1987 Vessel wall properties of the carotid artery in normotensive and borderline hypertensive young male volunteers. J Hypertension 5:S471-S473 